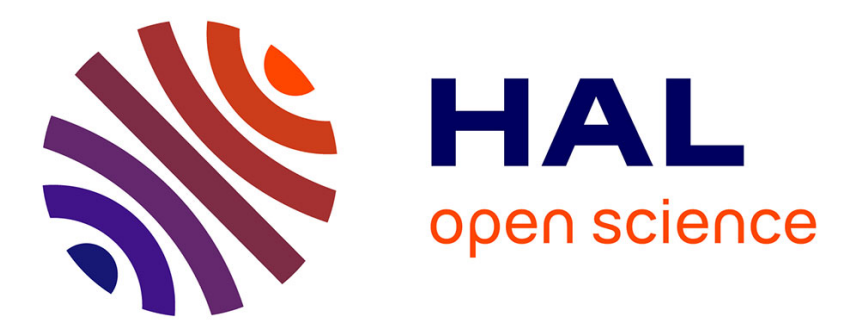

\title{
Collaborative Perspective in Bio-Economy Development: A Mixed Method Approach
}

\author{
Manfredi Vale, Marta Pantalone, Morena Bragagnolo
}

\section{To cite this version:}

Manfredi Vale, Marta Pantalone, Morena Bragagnolo. Collaborative Perspective in Bio-Economy Development: A Mixed Method Approach. 18th Working Conference on Virtual Enterprises (PROVE), Sep 2017, Vicenza, Italy. pp.553-563, 10.1007/978-3-319-65151-4_49 . hal-01674905

\section{HAL Id: hal-01674905 https://hal.inria.fr/hal-01674905}

Submitted on 3 Jan 2018

HAL is a multi-disciplinary open access archive for the deposit and dissemination of scientific research documents, whether they are published or not. The documents may come from teaching and research institutions in France or abroad, or from public or private research centers.
L'archive ouverte pluridisciplinaire HAL, est destinée au dépôt et à la diffusion de documents scientifiques de niveau recherche, publiés ou non, émanant des établissements d'enseignement et de recherche français ou étrangers, des laboratoires publics ou privés.

\section{(c)(1)}

Distributed under a Creative Commons Attribution| 4.0 International License 


\title{
Collaborative Perspective in Bio-economy Development: A Mixed Method Approach
}

\author{
Manfredi Vale ${ }^{1}$, Marta Pantalone ${ }^{2}$ and Morena Bragagnolo ${ }^{3}$ \\ ${ }^{1}$ Aghetera sas \\ ${ }^{2}$ Ca' Foscari University of Venice, Economic Dept. \\ ${ }^{3} \mathrm{Ca}$ ' Foscari University of Venice, Environmental Science, \\ Informatics and Statistics Dept., Italy
}

\begin{abstract}
The hybrid Economic Input Output - Life Cycle Assessment (EIOLCA) coupled with qualitative methods for consensus creation and participative policy building is a proposed methodology for dealing with complex and datarich contexts that have to be connected in order to construct a robust regional bioeconomic profile that informs policy makers and other stakeholders about socio-economic and ecological impacts - and suggest at the same time strategies for its validation and implementation. An important result of this work is that the process of data collection and systematisation also provided ample opportunity to be in touch with a wide and diverse range of actors that characterize the different supply chains, ranging from the primary (farming, aquatic resources, forest sector) to manufacturing and services-related companies. These contacts encouraged the establishment of a network exchanging knowledge on crucial aspects for the further development of bioeconomy.
\end{abstract}

Keywords: supply chains integration, economic input-output, life cycle analysis, sustainability, resilience.

\section{Introduction}

The concept of 'bioeconomy' is gathering momentum in European Union (EU) policy circles as a sustainable model of growth to reconcile continued wealth generation and employment with bio-based sustainable resources usage. Bio-based industries and bio-based products can represent a new development opportunity for European areas fighting with a still stagnating economy. The development of a bio-based economy is a long-term process that requires the involvement of many stakeholders on multiple levels and sectors [1] and could have great impacts on local communities. According to the definition of the European Commission, the bioeconomy comprises those parts of the economy that use renewable biological resources from land and sea - such as crops, forests, fish, animals and micro-organisms - to produce food, materials and energy [2]. Standing this wide definition, in order to strengthen its profile, it is necessary to bring into vision the main actors of the bioeconomy, primarily the companies that are taking action to achieve the objectives set by both the European Union and the United nations $[3 ; 4 ; 5]$. The bioeconomy is by and large an assemblage of regional activities that have their own regional character. For this reason, the choice of the most suitable strategy should be based on the involvement of 
all stakeholders [6], through participatory methods [7], that brings stakeholders together and let them confront each other on specific issues, agree on common meanings, and foreshadow a strategy for action. These participatory processes should empower participants to have an impact on the local/regional context, making them active in the strategic planning in the areas where they live, supporting the policymaking process in accordance with politicians, technocrats, lobbies and civil society groups. The aim is to find an agreement on development scenarios and a general strategy to pursue common interests, breaking the 'vicious circle of non-participation' [8]. The stakeholders are not always aware of their significant role in the co-creation of policies [9] and they need the support of methodologies that are able to promote their participation, encourage the interaction, and provide an operational synthesis of this process, leading to a strategy which could support the public decision-makers and policy-makers. The innovation beyond the state of the art of this project is to delineate and model the regional Bioeconomy with a hybrid Economic Input Output-Life Cycle Analysis (EIO-LCA) using statistical data of economic flows, conventional pollutants emissions, energy use, waste production of the 37 regional economic sectors (according to NACE1 classification) and integrate this information with sociological survey data collected during interviews and focus groups sessions.

The paper begins with a critical review of the literature on recent bio-economy impact-focused studies and on participative methods for policy design involving experts and diverse 'publics', thus suggesting that a mixed quantitative-qualitative approach is more appropriate for planning in highly complex contexts. The other sections present a synthetic description of methodologies and tools involved in this research, starting with an analysis of the baseline, as well as the main results on both disciplinary fields invoked, the economic-environmental modelling and the policy building through participative approaches. The concluding discussion recalls the importance of a mixed-method approach in order to better exploit its data richness and, at the same time, the importance of creating collaborative networks of different stakeholders in the field of bio-economy.

\section{Literature Review}

Bio-based products can include a diverse cross-section of items like enzymes; biobased end-use products; commodity, fine, and specialty chemicals; intermediates and polymers; feed, food and food additives; fuels; flavours and fragrances; pharmaceuticals; and bio-based energy. These products are woven into the economy in complex ways, making it difficult to compute the impact on the economy. Defining what will and will not be considered part of the core bioeconomy is important and has a great impact on the magnitude of various indicators of impact. For the bioeconomy to grow, many different segments of the economy must effectively interact. The connectedness of the bioeconomy can most easily be discussed in a supply chain framework. Supply chains are defined as all of the players involved in the movement of a product or service to the end customer. These networks transform natural

1. Statistical Classification of Economic Activities in the European Community 
resources into an end-use product, often via many different companies that add incremental value along the way $[10,11,12]$.

Input-Output modelling is a linear modelling approach which involves the examination of the economic cycle of production by analysing the relationship between the flow of production inputs and resultant flow/destination of outputs in an economy. Input-output analysis has received attention also as a means for delineating the bioeconomy development in Europe and abroad, with a number of works attempting to gauge the impacts that bioeconomy is producing and will produce in economic, environmental and social terms [13]. There are relatively few studies attempting a quantitative impact analysis of the existing and projected bioeconomy, also dealing with the problem of defining the scope, sectors and supply chains involved. An EU study [14] has attempted an economy-wide quantitative assessment covering the full diversity of the European bioeconomy by employing social accounting matrices (SAMs) for each EU27 member encompassing a highly disaggregated treatment of traditional 'bio-based' agricultural and food activities, as well as additional identifiable bioeconomic activities from the national accounts data. The aim was to profile and assess comparative structural patterns both across bioeconomic sectors and EU Member States. The results indicate six clusters of EU member countries with homogeneous bioeconomy structures. Irish researchers applied an input-output framework to define the scope of the national bioeconomy [15], thus establishing a Bio-Economy Input Output model $(B I O)$ which can be used to analyse the linkages between the bio-economy sectors and the wider economy. Two major strategies have been developed in recent years to develop the Agri-Food and Ocean Economy sectors in Ireland: the Food Wise 2025 and the Harnessing our Ocean Wealth strategies. The report contains analytical studies utilising BIO to quantify, among other things, the impact of reaching Food Wise 2025 growth scenarios and Harnessing our Ocean Wealth 2020 targets. Another work prepared for the U.S. Department of Agriculture and the Congress [16] seeks to answer questions regarding the contributions of the bio-based products industry in the United States: the quantity of biobased products sold; the value of the biobased products; the quantity of jobs created; the quantity of petroleum displaced; other environmental benefits; and areas in which the use or manufacturing of biobased products could be more effectively used.

The studies mentioned above highlight the data richness available on this matter and the need to capitalize on the wealth of information in order to promote policies effectively supporting the bioeconomy. The challenge to be grasped then becomes to "let the quantitative data speak" bringing it to the attention of those who, from different perspectives, work in the field of - or ar involved in - bioeconomy. The high uncertainty, of economic and regulatory nature, as well as the fact that it still mostly is a series of market niches, makes it necessary for the actors involved to identify a common glossary, a field of shared meanings that allows for the construction of alternative scenarios, in order to identify paths for collective action. Faced with the growing complexities of reality, the co-construction of bottom-up policies has taken hold in many fields $[17 ; 18 ; 19 ; 20]$. If planned and appropriately applied, participation can contribute to the design of policies and practices that are better suited to serving the needs of those concerned, that are perceived to be holistic and 
fair, accounting for a diversity of values and needs [21]. These processes increase the legitimacy of decisions taken and contribute in saving time in the long path due to lower resistance among stakeholders.

Starting from the above literature analysis and state of the art, this paper aims to answer the following research questions:

- RQ1 Identifying the sectors that make up the regional bio-economic mosaic;

- RQ2 (By using the EIO-LCA model): measuring the extent of the difference - in terms of environmental and socio-economic impacts - between conventional and bio-economic sectors;

- RQ3 (Starting from the living labs experience): building a network of inter-sectoral integration (combining agriculture, manufacturing and services) through a system of contractual guarantees that can be a model for developing the bioeconomy in Veneto region.

\section{Methods}

An Input-Output Analysis based approach for calculating environmental impacts of the economy that has become relatively widespread across the academic and institutional community around the themes of decision support systems is the Economic Input Output Analysis - Life cycle Assessment approach, based on Wassily Leontief's [22] I-O method for environmental analysis. The approach defines the whole economy as the boundary of analysis and uses transactions between industry sectors, along with environmental emissions data to determine the environmental impacts throughout supply chains within the economy. To answer the research questions we developed a hybrid Economic Input Output table (EIO) of the regional bioeconomy in a life cycle (LCA) perspective to make it available for the environmental and socio-economic ex-ante and ex-post assessments of (regional) plans and programs. The Veneto economy was taken into consideration as a whole to get a clear view of the bioeconomy; then, in cooperation with Unioncamere del Veneto and Emilia-Romagna (Regional Unions of Chambers of Commerce) and IRPET (Tuscany Regional Institute for Economic Planning) we identified through the Regional Input-Output Table (IOT) the sectors and companies that are momentarily the main bearers of the development of bioeconomy. Given the fact that the bioeconomy is a broad field, we decided to study a representative sample of Veneto companies (2000) with at least one product certified as organic, trying to strengthen a more respectful agriculture and transformation of raw materials. Therefore on a macroeconomic scale it makes sense to analyze such economic input/outputs and the corresponding interactions among organic and conventional supply chains by considering at the same time the pressures they exert on the environment and the socioeconomic system as a whole.

The process continued with the construction of a regional version of the NAMEA ${ }^{2}$ matrix (National Accounting Matrix including Environmental Accounts) for Veneto

2 The NAMEA consists of the framework of National Accounts with the supply and use of goods and services expressed in monetary units linked with integrated environmental accounts 
region (Italy) by disaggregating emissions based on a proxy variable defined as follows: number of employees per sector in Veneto Region compared to the total number of employees in the same sector in Italy. A second Matrix was derived from the regional Inventory of air emissions (INEMAR), 2013 version. This inventory estimates the municipal emissions of the main pollutants for each activity of the Corinair classification and type of fuel. Despite these figures can be considered more accurate than those obtained from the NAMEA data processing, they are aggregated according to categories not directly comparable with the classification of economic activities used to estimate the bioeconomy. The data available at INEMAR were processed to obtain results to be included in the NAMEA table. Three drivers of environmental pressures relate to: greenhouse categories (GWP); acidification (AP); ground-level ozone, while the 10 pollutants are: methane $\left(\mathrm{CH}_{4}\right)$, carbon monoxide (CO), carbon dioxide $\left(\mathrm{CO}_{2}\right)$, nitrous oxide $\left(\mathrm{N}_{2} \mathrm{O}\right)$, ammonia $\left(\mathrm{NH}_{3}\right)$, non-methane volatile organic compounds (NMVOC), nitrogen oxides $\left(\mathrm{NO}_{\mathrm{x}}\right)$, particulate matter (PM10 and PM2,5) and sulphur oxides $\left(\mathrm{SO}_{\mathrm{x}}\right)$.

For the socio-economic analysis, we involved stakeholders in focus group and brainstorming sessions, on one hand, and in depth interviews, on the other. Both these moments were crucial for sharing knowledge with experts (entrepreneurs, farmers, NGO's members, researchers), to putting together the distinctive visions from different stakeholders and to drawing possible policy actions. A first source of data comes from 3 case studies of companies (in the fields of bio-plastics, bio-food, biomaterials for the construction industry). The aim of these in-depth interviews was to analyse the characteristics of the 'bio-company', highlighting the economic and cultural context in which it operates. A second source of data comes from a Living Lab (LL) experience. Living Labs are open innovation platforms described as "functional regions where stakeholders have formed a Public-Private-Partnership of firms, public agencies, universities, institutes and people, all collaborating for creation, prototyping, validating and testing of new services, products and systems in real-life contexts" $[23 ; 24]$. One precondition of LL activities is that the innovation processes are strongly connected to real-world contexts, including exploration, experimentation, co-creation and evaluation with consumers in real life environments.

In the LL experience we involved all people who, at the local/regional level, felt themselves committed to the improvement of the bio-economy business as a whole. All people were recruited from participants to a European Union's Horizon 2020 coordination and support action (Bio-STEP) aimed at engaging citizens and various stakeholders in discussions about the future development of Europe's bioeconomy. The group was then expanded according to a snowball sampling procedures. The role of all these actors is significant not only when describing the problem, but also when pointing out for solutions and conditions to develop shared visions. Sadly, it appeared very difficult to get policy-makers involved. These participants were recruited first by phone, then through a one-to-one interview, and when interested, they received an email with a formal invitation to participate in focus group sessions or more in-depth interviews. The aim of this part of the study was to outline a set of policies that can

where the input of resources and output of emissions and pollutants are expressed in physical units. 
enhance best practices in order to coordinate and improve the effectiveness of bioeconomic actions. We collected the voices of different stakeholders and let them dialogue on different topics: the potential of networking with other bio-economic actors, the critical issues to be addressed in the bio business sector, the willingness to cooperate with other conventional and bio actors.

\section{Results}

In the case of Veneto Region for the year 2012 the IOT is a square matrix of $37 \times 37$ sectors representing how the various economic sectors are dependent on each other because in the columns and rows there are, respectively, the monetary values of their inputs and outputs. We notice that, despite the sector Crop and animal production, forestry, hunting and related services consists of more than half of the companies identified as contributors to the Venetian bioeconomy, it represents one of the sectors with less information available: hardly ever these are capital companies and then budget information is not available on the databases available so far. By coupling the Economic Input Output (EI-O) table with the RAMEA (Regional Accounting Matrix including Environmental Accounts) it has been possible to extend the previously existing knowledge about direct and indirect environmental impacts: the ratio of value added for the whole economy compared with that of each of the bioeconomic sectors comprised in our sample of some 2000 companies has been used to estimate the impacts associated with bioeconomy in a life cycle perspective (LCA). Moreover, it is possible to further separate the contribution of final demand by distinguishing e.g. the internal aggregated one from that generated by the exports. By carefully screening the results of this combination of economic and environmental information, it is possible to select out of the 37 "canonical" IO industry categories, those economic sectors that at this stage (data refers to year 2012) a) are/were referable to bioeconomy and b) showed significant potential impacts - associated with the emissions to the atmosphere - on one or more standard impact categories. Some overestimation is possible under e.g. the NACE 'Manufacture of food products, beverages etc.' where the relatively high ratio of bioeconomic activities on the total is due to the inclusion in the calculations of conglomerated realities of large-scale distribution retailers with their massive turnovers, despite the transition to organic is rapid but still partial indeed. Other sectors of interest for the regional bioeconomy are obviously 'Crop and animal production' (despite the very low added value, which still is one of the issues of the "average" agricultural supply chain in Italy and Veneto), the 'Manufacture of coke and oil' (similar argument to the one concerning retail chains) - that is partially converting to renewables - 'Rubber and plastic products', 'Wholesale and retail trade', 'Accommodation and food service activities'. The same applies to the export quota of demand. By referring to e.g. the manufacture of food products, the pressure exerted from the export quota in terms of direct and indirect emissions is on average higher for an order of magnitude when compared with emissions produced by the internal regional demand. This is not strange for highly internationalized economies as the Veneto one ${ }^{3}$. When moving from emissions to the associated potential impacts through dedicated LCA software, it is possible to quantitatively measure the

3 http://venetointernazionale.it/ 
proportion of the Venetian bioeconomy as an aggregate of multiple supply chains compared with the regional economy as regards to Global warming, Acidification, Nutrient Enrichment and Photochemical Ozone Formation (see figure 1).
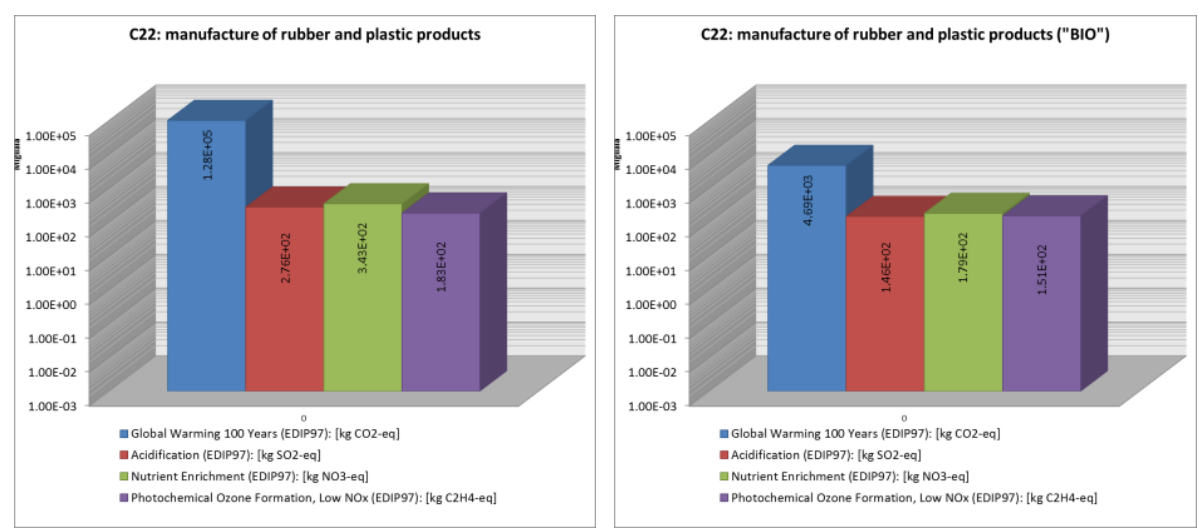

Fig. 1. Main impact categories associated with the emissions of conventional vs bio-based rubber and plastics production (logarithmic scale; ordered: values in thousands).

Definitely our sample of 2000 companies when compared with the total number of companies in Veneto represents $0.4 \%$. The data obtained from this first estimate shows that the bioeconomy in Veneto has an interesting growth potential, representing, in terms of added value, $2.86 \%$ of the regional total.

So, what are the policies that, according to stakeholders, can help the increase of Veneto's bio-economic sector?

The in-depth interviews and case studies on bio factories have allowed us to outline the economic and cultural context within which bio activity in Veneto is developing. These markets are "niches", populated by a few or very few actors ${ }^{4}$ (at national, European and international level). In this niches, because of the low number of actors and the strong ethical instances of some key players, the competition assumes a peculiar characteristic: it becomes "Coopetition", a hybrid between cooperation and competition that brings to light the positive results of the first concept while not losing the characteristics of the latter. Being very few, these companies may not be subject to the "mors tua, vita mea" rule, which regulates the conventional markets, but, while not abandoning the logic of profit, they can adopt ethical behaviors by which all can implement their profits minimizing losses (win-win logic).

The adoption of this logic has enabled companies, once they enter their market niche, to raise its standards. Rigorous controls on raw materials and production processes, with the aim of certifying their product as organic or their processes as

4 From the case study on bio-building factory emerges that in this field the analyzed enterprise is unique in its kind in Italy by the type of product proposed and, at international level, is one of the six existing in the field. Similar numbers are also found in relation to the production of bioplastic materials. 
sustainable, have introduced virtuous logics between competitors, creating a "standard upgrade process" aimed at giving the consumer more trustworthy products. It is the consumer's trust in the product, which allows the company to remain on the market, even though the price of their product is even three times higher than the conventional product. According to entrepreneurs, such trust is building up by taking care of the "moral" integrity of the company and its mission.

The possibility of building a cooperative network between the different actors in the field of bio-economy (not only businessmen, but also researchers, cultural associations, professionals) was assessed with the group work in the Living Lab sessions. One thing, in fact, is to analyze the single bio-realities individually considered, and another to analyze the possibility that they work together. The first hurdle has proved to be eminently cultural in a territory, such as the Italian north-east, made of small-medium businesses, often family-run.

The group work between different stakeholders has highlighted the need to implement policies:

1. for the creation of a network of bio actors [e.g. a) Provide a common glossary to match the language with which reference is made to the activities carried out or b) adopt an ethical code that protects patents and original ideas and prevents opportunistic behaviors];

2. for the consolidation of relationships with other actors [e.g. a) with the university research, in order to create dialogue between the world of production and the world of scientific research and to optimize and finalize the resources in programs that have then possible productive effects (systems, biomaterials, crops) or b) for vertical and horizontal integration of the supply chain, with the aim of building certified chains from the producer to the consumer.

It is, in this sense, to create the background for dialogue among niche markets and to ensure that individual actors are no longer "dwarfs" in a giant world (the 'conventional' one), but part of a cooperative network getting more and more resilient. The restructuring of the bio-economic sectors, in fact, moves the "power" on who, normally, does not have it: small producers (farmers, breeders), consumers, the civil society and their networks.

\section{Conclusions}

This research project has allowed to more reliably gauge the value of bioeconomy - a complex and data-rich aggregation of market niches - beyond its current economic and monetary weight in the Veneto region. The theme of the higher value of bioproducts and bio-supply chains has emerged, as well as the ongoing process of rebalancing supply chains and giving more power to historically disadvantaged stakeholders.

From an economic point of view, the adoption of a mixed approach has highlighted the sectors linked to bio-economy as showing higher value of production, higher added value and lower staff turnover, but at the same time they still account for only $0.4 \%$ of the total number of companies in the region and in many cases they are converting imported raw materials - from other regions or from the rest of the world because regional production does not meet their demand. 
From an environmental point of view, according to the first outcomes of the EIOLCA analysis, there is evidence - across some sample bioeconomic supply chains - of reduced environmental impacts; however, further analyses are required to confirm those insights, both at the sectors' and system scale.

From a sociologic point of view, it has emerged that the true drivers of change are relatively small economic actors (both on the demand and supply side) capable of raising standards across the entire industry and promoting at the same time its resilience. Within these market niches, those actors are capable of imposing their "regulatory discipline" to other actors, going beyond their own boundaries and influencing the whole sector. These 'little ones' - being a cultural and knowledgeintensive avant-garde - demonstrate the link between culture, ethical instances, coopetition capacity, networking potential, increased resilience, win-win logic. Culture has in fact demonstrated to be the hidden engine behind this change of paradigm towards bioeconomy: familiar and entrepreneurial culture often dates back to the last century in Italy, with a very clear distinction between family and business, being still today the main prerequisite towards business managerialisation and development in this geographic area. Another important driver of change are consumers who, with their behaviours in terms of preferences and demand, affect and redirect the market, thus indicating in advance to the regulators the direction of future policies. Conversely, politicians are perhaps those less capable of vision and innovation among the various stakeholders, and tend to hardly chase the progress of others.

All of the above boils down to a very first attempt of defining an operational/managerial model which moves from the academic interaction of sciences and humanities - having realized that none of the two disciplinary fields can be exhaustive by itself - towards a hybrid approach to big (and diversified) data management that allows for the definition of a measurable link between knowledge based and aware business management, increasing environmental performance - at the product and process scale - and a corresponding improvement of socioeconomic performance.

\section{References}

1. Munda, G.: Social multi-criteria evaluation: Methodological foundations and operational consequences. European Journal of Operational Research, 158, 662-677 (2004)

2. European Union, Innovating for Sustainable Growth. A Bioeconomy for Europe. Directorate-General for Research and Innovation (2012)

3. United Nations (2016), Sustainable Development Goals. http://www.un.org/sustainabledevelopment/sustainable-development-goals/

4. McCormick K., Kautto N.: The Bioeconomy in Europe: An Overview. Sustainability 2013, 5, 2589-2608. http://www.mdpi.com/2071-1050/5/6/2589 (2013)

5. European Commission: Commission proposes strategy for sustainable bioeconomy in Europe http://europa.eu/rapid/press-release_IP-12-124_en.htm (2012)

6. Patel, M., Kok, K., \& Rothman, D. S.: Participatory scenario construction in land use analysis: An insight into the experiences created by stakeholder involvement in the Northern Mediterranean. Land Use Policy, 24, 546-561: 2007) 
7. Lopolito, A., Nardone, G., Prosperi, M., Sisto, R., \& Stasi, A.: Modeling the bio-refinery industry in rural areas: A participatory approach for policy options comparison. Ecological Economics, 72, 18-27 (2011)

8. Sisto R., van Vliet M., Prosperi M.: Puzzling stakeholder views for long-term planning in the bio-economy: A back-casting application, Futures 76, 42-54 (2016)

9. Odugbemi S., JacobsoonT.: Governance reform under real world conditions. Citizens, stakeholders, and voice. Washington, DC: The International bank for Reconstruction and Development/The World Bank (2008)

10. United States Department of Agriculture (2011), Biobased economy indicators, available at https://www.usda.gov/oce/reports/energy/USDA\%20Bioindicators982011 2.pdf

11. Macchion L., Moretto A., Caniato F., Caridi M., Danese P., Spina G. \& Vinelli A.: Improving innovation performance through environmental practices in the fashion industry: the moderating effect of internationalisation and the influence of collaboration, Production Planning \& Control, pp.1-12 (2016)

12. Lion A., Macchion L., Danese P. and VinelliA.: Sustainability approaches within the fashion industry: the supplier perspective, Supply Chain Forum: An International Journal, vol.17, no.2, pp.95-108 (2016)

13. Vagnani G., Volpe L.: Alla ricerca del valore della filiera vitivinicola: verso la formulazione di un modello di analisi, Mercati e Competitività n. 4, pp.21-43 (2009)

14. Philippidis G., Sanjuán A.I., Ferrari E. and M'barek R.: Employing social accounting matrix multipliers to profile the bioeconomy in the EU member states: is there a structural pattern?, Spanish Journal of Agricultural Research 2014 12(4): $913-926$

15. Grealis and O'Donoghue (2015), The Bio-Economy Input-Output Model: Development and Uses www.nuigalway.ie/semru/documents/economic impact of the irish bioeconomy $07 \quad 10$ $\underline{15 . \mathrm{pdf}}$

16. Golden J.S., Handfield R.B., Daystar J., McConnell T.E.: An Economic Impact Analysis of the U.S. Biobased Products Industry: A Report to the Congress of the United States of America. A Joint Publication of the Duke Center for Sustainability \& Commerce and the Supply Chain Resource Cooperative at North Carolina State University (2015)

17. Claude S., Ginestet S., Bonhomme M., Moulène N., Escadeillas G.: The Living Lab methodology for complex environments: Insights from the thermal refurbishment of a historical district in the city of Cahors, France, Energy Res Soc Sci (2017)

18. Lepik K., Krigul M., Terk E., Introducing Living Lab's Method as Knowledge Transfer from one Socio-Institutional Context to another: Evidence from Helsinki-Tallinn CrossBorder Region, Journal of Universal Computer Science, vol. 16, no. 8, 1089-1101, (2010)

19. Liedtke C., Welfens M.J., Rohn H., Nordmann J.: LIVING LAB: user-driven innovation for sustainability, International Journal of Sustainability in Higher Education, Vol. 13 Iss 2 pp. $106-118$

20. Canzler W., Engels F., Rogge J., Simon D., Wentland A.: From "living lab" to strategic action field: Bringing together energy, mobility, and Information Technology in Germany, Energy Research \& Social Science 27, 25-35 (2017)

21. Gruszka, K.: Framing the collaborative economy - Voices of contestation. Environmental Innovation and Societal Transitions (2016)

22. Leontief W.: Environmental Repercussion and the economic structure: an input output approach. In The review of Economics and Statistcs; 1970, The MIT Press p. 263-271

23. Almirall, E., Wareham, J.: Living labs and open innovation: Roles and applicability. The Electronic Journal of Virtual Organizations and Networks (EJov), 10, 22-46

24. Wendin K., Åström A., Ståhlbröst A.: Exploring differences between central located test and home use test in a living lab context, International Journal of Consumer Studies 39 230-238 (2015) 